\title{
Problems of competence-based learning in a digital environment
}

\author{
Nadezhda Efremova* \\ Don State Technical University, 344000, Rostov-on-Don, Russia
}

\begin{abstract}
In the system of higher education the main results of mastering the basic educational programs are the competences of students and graduates. However, in the pedagogical environment, despite the widespread use of the term, there is still no deep understanding of the features of such results and ways to achieve them. Therefore, there is often no clear distinction between cognitive outcomes (knowledge, skills, and abilities) and competence outcomes. There are difficulties in taking into account both conditions and principles of competence formation and specifics of control and assessment process organization to reliably identify the levels of students' competence formation. The article gives a brief overview of the existing concepts of competences, their specificity, conditions of their formation and assessment. It is shown that competences reflect students' abilities to act productively in a problem situation, using knowledge, abilities, and skills to achieve the target result. The intensive development of digital technologies creates additional opportunities and problems not only for distance learning, but also for creating new conditions for assessing learning achievements, including competences, in the virtual environment of digital space. The importance of developing a methodology for competency-based learning, including the use of digital capabilities, is emphasized. It is noted that, despite the many important and necessary tools of the digital space, there are also negative aspects of their use, which should be taken into account in the construction of educational content.
\end{abstract}

\section{Introduction}

In today's digital world, the need for highly skilled workers is increasing, society's demand for the quality of professional education is changing, and the mismatch between the qualifications of graduates and the qualifications required by employers is increasing. They are primarily interested in graduates' readiness to start productive activities immediately after graduation, and, accordingly, the requirements to learning outcomes are changing. In their eyes the quality of a specialist is determined by such characteristics as: active life position, motivation to improve profession, ability to self-development, leadership, ability to work in a group, creativity and communication. Employers want successful employees, because the success of the organization directly depends on the achievements of its employees. And the success of an individual today is not only determined by the body of

* Corresponding author: nefremova61@donstu.ru 
learned knowledge, although it always has been and always will be important, because without it, of course, you can't be successful. But it becomes insufficient, assimilated or received from various sources knowledge may remain unclaimed and unrealizable without such properties of personality as competences and skills of the XXI century. Therefore, there is a rethinking of the forms and methods of organizing and conducting educational activities, the results of professional education are changing.

Studies show that business qualities and personal competencies of graduates are the most in demand, and only after that qualification achievements [1-3]. Even the ancient Greek philosopher Aeschylus in the 5th century B.C. expressed this formula: wise is not the one who knows much, but the one whose knowledge is useful (let us add, and skillfully used). The general idea of competence has been around for a long time. Stating that learning outcomes and diplomas do not guarantee effective performance and success in life, David McClelland (1973) introduced a new notion of learning outcomes and became the founder of the competence theory. He believed that the prediction of job performance could be provided by a reliable assessment of competencies [4]. What is "competence"? There are many definitions of competence in foreign and domestic literature, such as: a basic quality of an individual causally related to effective and/or best on the basis of criteria performance at work or in other situations (Lyle and Cine Spencer, 2005) [5]; characteristics of an individual causally related to effective performance (Boyatzis, 1982) [6]; behavior in effective task performance (Whiddett, Hollyforde, 2003) [7], etc. All of them agree in one thing - it is a connection of certain qualities of the personality, its behavior and successful activity.

The terms, concepts and definitions of the competence format are actively used in publications and normative documents on education, but in actual educational practice the traditional knowledge-based approach with a focus on cognitive learning outcomes is mostly used. This can be explained by the fact that the wording developed in the framework of the implementation of the Bologna requirements to the results is given in terms of competencies, and the whole educational system has been connected with the transfer of information and traditional control of its assimilation by many years of practice. It is practically impossible to change the learning system in a short period of time, so currently there is a kind of transition period.

The purpose of the article is to analyze the existing ideas about competencies, their properties, the principles of formation and evaluation, including the digital environment.

\section{Problems}

The problems of divergence between the theory and practice of competency-based education are due to the fact that most university teachers and school teachers have not yet developed an understanding of the specific features of competencies, their complex structure and deeply latent nature, interdisciplinary nature, requiring special conditions for their formation and assessment. However, as long as there is no understanding of the specificity of competencies, there can be no full-fledged competency-based learning. Many years of experience with the audience of teachers show that most often competences are understood as a sum of knowledge, skills and abilities, introduced by Jan Amos Comenius in the middle of XVII century (1633-38). However, this is not entirely true; competences are not so straightforward. It is the irreducibility of the sum of the properties of individual elements into a system property. Competences are not a simple sum of cognitive outcomes knowledge, abilities, and skills are only a necessary basis for their formation, because competences are not formed without knowledge and outside activities, and knowledge does not manifest itself without competences. Due to emergent nature, fundamentally new functional properties of a personality in the form of competences are formed on the basis of 
this basis in the process of active productive activity. Such a result provides the subject with the ability to act and solve arising problems. That is why active (activity-based) forms of learning and guided independent work acquire special relevance. According to I.A. Zimnya (2004) competences are mental emotional and behavioral newformations formed in students in the process of productive activity [8].

The seeming simplicity of introducing competencies into the educational process distorts the essence of modern requirements for competency-based learning outcomes. As a result, in most cases, the test of mastering the content of disciplines, including the results of testing, is passed off as an assessment of competence formation. But testing by its very nature cannot identify competences, it is designed only to test knowledge and, to a lesser extent, any skills. Testing is not a universal assessment tool and has its own limit [9-11]. An exam or other ad hoc assessment procedure also cannot identify and assess the level of competence formation. The introduction of competency-based approach in educational practice raises the problem of developing a competency-based learning methodology and assessing its results.

The digital transformation of education also requires significant updating of both planned educational outcomes and educational content, providing methods and organizational forms of student activities in learning situations, new pedagogical practices, development of new tools and technologies for evaluating the results achieved. At the same time, when using digital technology, certain risks should be taken into account. These include possible health problems and loss of social skills. We cannot rule out violations of the authenticity of information and changes in the educational content; not all subject and content areas can be mastered remotely, you cannot learn remotely to be an architect, programmer, jeweler, surgeon, midwife, pilot, actor, designer, teacher and many others (about 200 professions). At the moment there is a weak methodological organization of training and evaluation of its results in the digital space.

\section{Results}

The deep latency and interdisciplinarity of competences create certain difficulties in their formation, observation, identification and assessment. The latent nature of competencies, as personal new formations, is manifested to a greater or lesser extent in the process of various activities and controls, each of which can be assessed in points. McClelland believed [4] that when assessing competences it is necessary to use incomplete situations, so that the student has an opportunity to generate his behavior in an unstructured situation or the way he behaved in similar situations. The interdisciplinary nature of competencies is manifested in the fact that they are not formed by a single discipline, but, as a rule, by a set of related disciplines. In turn, each discipline contributes to the formation of several competences of the same type. Another important feature of competencies is their supra-subject or transferable nature, when they acquired in one subject area can manifest and be used in another one. Therefore, it can be difficult to distinguish which discipline contributed to the learning outcome. To a greater extent, this applies to universal, systemic, and instrumental competencies.

That is why the formation of educational programs is preferable in the modular-cluster form [12], when disciplines of related content are combined into modules, and similar competences into clusters, formed as a result of learning module. In this case a module is understood as a group of disciplines involved in the formation of competencies united in a cluster. After mastering the training module it is possible to assess the cluster of competencies based on the results of multistage assessments or performance of a complex interdisciplinarytask. Its implementation requires certain activities: performance of individual or group projects or case study tasks; creation and presentation of presentations 
on a given topic in the group; obtaining activity products in accordance with the specifics of the training program. Because of all this the verbs "to know", "to be able" and "to possess" reflect only the results of the traditional cognitive approach to learning (potential), and the competence approach corresponds to the appearance of psychological qualities of personality, described by the phrase "to be able to do".

How subject characteristics are identified in an activity-based assessment situation, how these extractions are evaluated, and how scores are accumulated is shown in EvidenceCentered Design models of reasoned evidence for making valid evaluative judgments (Mislevy, Almond, \& Lukas, 2003)[13-15]. Assessment designers on this model are able to create a set of evidence that reflects what the student knows and can do.

Simple tasks can act as a platform for 21 st century skills while supporting the technical infrastructure associated with the computer-based assessment capabilities of 21 st century skills. The design of the assessment tool requires the selection of tasks from the total amount of controlled material and the selection of appropriate situations to provide activity and representativeness of information about the preparedness of the examinees to prove the specific achievements of the learners and the validity of the assessment. Specific conditions and technologies are needed for assessing competencies.

It specifies how many and what types of tasks will be used to assess each statement, within what limits statements will be selected, and what additional evidence of psychometric quality and instrument validity is provided to achieve reliable results in the assessment process. The question "why we measure" will be answered by the student model of knowledge and competencies; the question "how we measure" will be answered by the evidence model; "what we measure" will be answered by the task model; "what we measure" by the assessment tool; "how we provide results analysis" by the protocol formats. The extraction of attributes of competence formation is provided on the basis of observation data, including both process and product variables.

The evidence model combines a model of examinee characteristics and a model of the task, describing what is to be revealed, how to reveal, and how to combine scores with observations and evidence (Fig. 1).

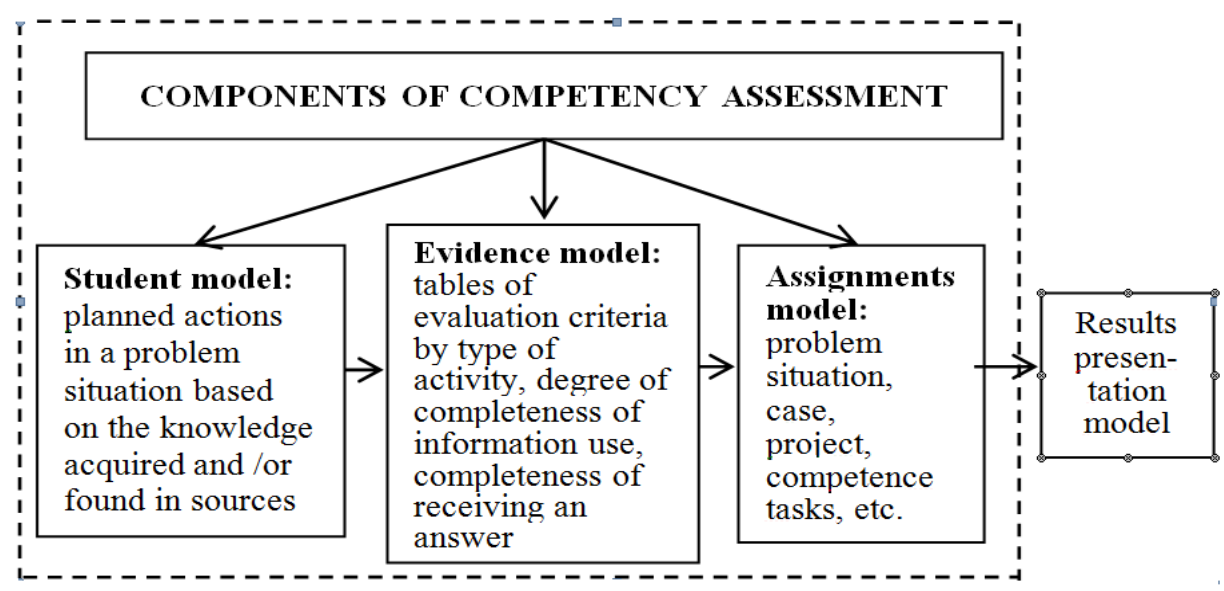

Fig. 1. Conceptual framework for assessing competencies.

The development of tools and sequence of developers to organize and conduct assessment of competencies of students consists of a fairly large number of stages:

- definition of the assessment goal, the choice of the subject of measurement (one or more latent characteristics of the object of observation) and the construct (one or more 
competencies), where the goal is seen as ensuring the unity of motives, means and results of the assessment;

- analysis of the structure of competencies and selection of assessed characteristics of objects, a multidimensional construct is compiled from competencies and assessment levels or other attributes with reliance on a certain amount of necessary knowledge;

- construction of a measurement model and operationalization of constructs to ensure the processing and use of results;

- development of a conceptual framework for assessment tools, consisting of a description of competency levels in terms of descriptors; observable variables and instructions on how to assess them; indicators of task completeness;

- selection of professionally interesting situations for constructing the task and organizing students' activities in an assessment situation;

- justification of how many tasks are needed for the design of the assessment tool, what actions students must perform, and what solutions to give;

- preparing the format of the answer sheet for the assignment;

- justification of the level scale, threshold scores and achievement criteria;

- providing a comfortable environment for the evaluation process and its representation, observation and collection of evidence of the student's activity in completing the assignment;

- processing the results and presenting the data in a user-friendly form.

All student activities are evaluated in points, which are summarized and displayed on a level scale, providing opportunities for analysis and interpretation of the results.

\section{Discussion}

A reliable representation of what students know and can do is more difficult than traditional testing methods. Assessment of problem solving in a high-tech environment without the use of computer simulation, animation experiment and digital technology, and scientific inquiry skills is particularly challenging $[16,17]$. High quality assessments are achieved by a set of measures that ensure reliability, validity, and authenticity of the results. The first one shows the measure of objectivity of the measurement results, and the second one shows their measure of compliance with the goal of the assessment process, and the third one should ensure that the result of the assessment corresponds to the test taker's preparedness. In foreign educational practice multistage assessments are carried out to identify competences, complex tasks and multilevel scales are used [18]. Multistage assessment is provided by taking into account the results of various assessment procedures of current control (tests, cases, projects, surveys, presentations, coursework, etc.) and intermediate attestation. The greater the variety of assessment tools and the greater the number of activities included in the performance of tasks (especially complex ones), the more adequately reflects the competence level. After mastering the module, the scores of assessments of different activities are summed up, and the result obtained is displayed on the level scale, on which a set of scores and given (criterion) threshold values determine that the competence is formed at basic, advanced or high level. For this purpose unidimensional or multidimensional scales can be used depending on the purposes of assessment, complexity of the construct and assessment tools. The complexity of this procedure corresponds to the complexity of the assessed object. Complicating the situation is the lack of research and consensus on how best to teach these skills and how they can be assessed fairly (Herman, 2017).

Griffin P. (Griffin Patrick, 2015) argues that a probabilistic interpretation of competence can provide a framework for linking assessment, learning, curriculum resources, and educational policy development [19]. However, traditional assessment methods typically 
measure individual outcomes rather than team outcomes, failing to assess learner competencies, attitudes, and characteristics, achievement of independent and collaborative learning. These skills are difficult to characterize and measure, but they are more critical than ever for future professional performance. Creating and introducing a new assessment and evaluation system is a major challenge that requires effort, resources and experience, special training of implementers, and significant financial and material resources.

New virtual learning environments include more spaces and practices, and therefore the use of complex tasks is preferable because they involve several processes that allow integration and control of student activities. Forms of organizing student activities can be case solving, epistemic games, performing individual and group projects, presentations, etc. With the accumulation of large data sets generated in digital learning environments, statistical processing can be used, offering information about students' interactions with the system, which allows tracking and identifying the processes of students' independent learning [20, 21]. New virtual learning environments include more spaces and practices, and assessment of student activities in digital learning environments has great potential for collaborative problem solving, and is also applicable to multimodal learning outcome analytics [22-24].

\section{Conclusion}

In the light of all the above, it is clear that competency-based didactics has not yet been formed, teaching and control processes require teachers to clearly understand the latent nature and complex structure of competencies, extensive application of activity-based methods in the educational process. Researchers and practitioners have yet to develop methodological, methodological and technological approaches to the formation and assessment of competencies, taking into account their specific features and the need to work in the digital space. Forms and methods of teaching students should provide fundamentality of education and a set of necessary competences, which are systemic for formation of a competitive specialist. That is why it is so important for teachers to have certain competences, if a teacher does not have them himself, he/she will not be able to teach them to students. The development and implementation of competency-based education requires a lot of efforts and time, material and intellectual support, but the dynamics of the society development does not leave another way and alternative to competency-based education. A new trend is emerging in the theory of learning - "digital pedagogy", which should integrate, complement and develop the best examples of educational activity: practice-oriented methods, the use of digital content and ecosystems of services to provide individualization of students' educational trajectories. Today, a unified digital environment is being formed, consolidating educational and research content; digital services are being developed, providing internal and external interactions for all user groups. Therefore, it is necessary to purposefully improve the digital competencies of all categories of employees of educational institutions, first and foremost the teaching and academic staff.

\section{References}

1. Yu.A. Dmitrieva, Human Resource Management 2, 67-75 (2010).

2. D.A. Konoplyansky, Higher Education Today 11, 23-26 (2016).

3. V.E. Gromov, G.A. Gromova, A.D. Ivanova, O.V. Murugova, Scientific Review. Pedagogical Sciences 4, 5-10 (2018).

4. D.C. McClelland, American Psychologist 28 (1), 1-14 (1973). 
5. Jr. Lyle M. Spencer, M. Syne Spencer, Competencies at work (HIPPO, 2005).

6. R.E. Boyatzis, The Competent Manager: A Model for Effective Performance (John Wiley \& Sons, New York, 1982).

7. S. Whiddett, S. Hollyforde, A Practical Guide to Competencies: How to Enhance Individual and Organisational Performance (CIPD Publishin, 2003).

8. I.A. Zimnyaya, Key competencies as an effective-target basis of a competence-based approach in education (ICPKPS, 2004).

9. N.F. Efremova, Pedagogical Measurements 1, 25-31 (2016).

10. E.F. Efremova, Competencies in Education: Formation and Assessment (National Education, 2012).

11. R.E. Boyatzis, Journal of Management Development 27 (1), 5-12 (2008). doi.org/10.1108/02621710810840730

12. N.F. Efremova, Higher Education Today 10, 12-17 (2018). doi: 10.25586 / RNU.HET.18.10.P.00

13. R. J. Mislevy, R.G. Almond, J.F. Lukas, (ETS Research Report RR-03-16), Princeton, NJ: Educational Testing Service 37, (2003).

14. R.J. Mislevy, G. Haertel, M. Riconscente, D. Rutstein, C. Ziker, A Suite of ResearchBased Design Patterns, Springer, 2017.

15. A.A. Rupp, M. Gushta, R.J. Mislevy, D.W. Shaffer, Journal of Technology, Learning, and Assessment 8 (4), 44 (2010).

16. R.E. Bennett, F.J. Hilary, P.A. Weiss, Assessment in Education Principles Policy and Practice 23 (2003). doi: 10.1080 / 0969594032000148181

17. Milan Jaros, American Journal of Educational Research 2 (10), 898-905 (2014). doi: 10.12691 / education-2-10-8.

18. V.I. Zvonnikov, A.A. Malygin, M.B. Chelyshkova, Izvestiya vuzov. Humanities Series 5 (2), 166-171 (2014).

19. P. Griffin, E. Care (eds.), Assessment and Teaching of 21 st Century Skills (Springer, 2015).

20. H.L. Banerjee, V. Timpe-Laughlin, ETS Research Memorandum Series. RM-19-01, 37 (2019). Princeton, NJ: Educational Testing Service.

21. M. Cukurova, M. Mavrikis, R. Luckin, UCL Knowledge Lab, University College London 22 (2017).

22. E. Murugova, T. Mikheeva, E3S Web of Conferences 210, 18095 (2020). doi: https://doi.org/10.1051/e3sconf/202021018095

23. Esther Care, Helyn Kim, Alvin Vista, Kate Anderson, Education System Alignment for 21st Century Skills: Focus on Assessment. Optimizing Assessment for All, Brookings 41 (2018). doi: 10.4995/head20.2020.10984

24. P. Ermakov, E. Vorobyeva, E. Kovsh, S. Shlyk, F. Khakunova, A. Bersirova, M. Dalgatov, E3S Web of Conferences 210, 19023 (2020). DOI https://doi.org/10.1051/e3sconf/202021019023 